\section{(}

OPEN ACCESS

EDITORES

- Marcus Maia (UFRJ)

- Bruna Franchetto (UFRJ)

AVALIADORES

- Beatriz Protti Christino (UFRJ)

- Bruna Franchetto (UFRJ)

SOBRE OS AUTORES

- Idiane Kariri-Xocó Conceptualização, Escrita Rascunho Original e Escrita Análise e Edição.

- Nhenety Kariri-Xocó Conceptualização, Escrita Rascunho Original e Escrita Análise e Edição.

- Diane Nelson

Conceptualização, Escrita Rascunho Original e Escrita Análise e Edição.

- Thea Pitman

Conceptualização, Escrita Rascunho Original e Escrita Análise e Edição.

DATAS

- Recebido: 30/05/2020

- Aceito: 05/10/2020

- Publicado: 29/12/2020

\section{COMO CITAR}

KARIRI-XOCÓ, I; KARIRI-XOCÓ, N.; NELSON, D.; PITMAN, T. (2020). A retomada da língua kariri-xocó. Cadernos de Linguística, v. 1, n. 3, p. 01 13.

\title{
A RETOMADA DA LÍNGUA KARIRI-XOCÓ
}

\author{
Idiane KARIRI-XOCÓ (DD
}

Subatekié Nhunú Kariri-Xocó

Nhenety KARIRI-XOCÓ iD $\boldsymbol{\Delta}$

Guardião das Tradições da Comunidade Kariri-Xocó

\section{Diane NELSON iD $\boldsymbol{X}$ \\ Universidade de Leeds \\ Thea PITMAN D $\boldsymbol{D}$ \\ Universidade de Leeds}

\section{RESUMO}

Desde 1989, a comunidade indígena Kariri-Xocó do estado de Alagoas, Brasil, se envolve em um processo singular de revitalização cultural. Trabalhamos para recuperar nossa língua ancestral, aproveitando as memórias da comunidade por meio de músicas, histórias e rituais, preenchendo assim lacunas em nosso vocabulário. Alguns de nós distribuímos listas de palavras para jovens e adultos da comunidade via WhatsApp, enquanto outros abriram uma escola para ensinar a língua a crianças mais novas. Este documento discutirá o processo de revitalização da língua da nossa comunidade. Em particular, veremos como nossa comunidade está aproveitando as mídias digitais para coletar, criar, disseminar e ensinar nossa língua como um meio importante de reforçar nossa identidade cultural.

\section{ABSTRACT}

Since 1989 the Kariri-Xocó indigenous community of Alagoas state, Brazil, has been engaged in a unique process of cultural revitalisation. We have 
been working to bring back our ancestral language by drawing on community memories of the language through songs, stories and rituals, thus filling gaps in our vocabulary. Some of us circulate word lists to young people and adults in the community via WhatsApp, while others of us have opened a language school to teach the language to younger children. This paper will discuss our community's process of language revitalisation. In particular, we will look at how our community is harnessing digital media to collect, create, disseminate and teach our language as an important means of reinforcing our cultural identity.

\section{PALAVRAS-CHAVE}

Revitalização Linguística; Línguas Indígenas; Kariri-Xocó; Tronco MacroJê; Dzubukuá-Kipeá; Alagoas.

\section{KEYWORDS}

Language Revitalisation; Indigenous Languages; Kariri-Xocó; Macro-Jê Languages; Dzubukuá-Kipeá; Alagoas. 


\section{PALAVRAS DE BOAS-VINDAS DE IDIANE}

Kanghy kieretú mó wohoyé. Yetçã ká Idiane, dubo-eri ayby nunú kariri xocó. Yetçã pidé moyghy mó ayby swbatekié ay wohoyé ey, karay ayby kanghy kerú andé yetçãmy moyghy corã. Tçohó karay dó mé dó yetçãndé ninhó kariri xocó. Kié tçohó nunú. Yetçandé tçohó nunú, nió. Yetçã ynhahó Eridzá swbatekié mó wohoyé ey.

Hiwibaedé morochy crody anrá swbatekié ayby dzudé nunú. Yetçandé kariri xocó ybôà bihé tsohó buyõ crody ayby Nhenety. Tçohó yrasichy tçohó woroy. Ey saerae swbatekié, doró teró naté sembohó kariri xocó. Buyõ ynatekié.

Boa tarde para todos. Eu me chamo Idiane, professora da língua Kariri-Xocó. Eu estou aqui para dar conhecimento a todos vocês, brancos de bom coração e parentes aqui presentes.

Tem branco que fala que nós Kariri-Xocó não temos língua. Nós temos língua, sim. Eu levarei esse conhecimento para todos vocês.

Eis de ir firmes e fortes no conhecimento da nossa língua. Nós Kariri-Xocó somos um povo muito forte, de tradição. Temos cultura, temos história. Vocês querem conhecimento, então venham a trabalhar com os Kariri-Xocó. Muito obrigada.

\section{CONSIDERAÇÕES INICIAIS}

Este artigo explora como nós Kariri-Xocó estamos revitalizando nossa língua, a base das memórias da comunidade e das tradições sagradas expressadas nos Torés e nos rituais do Ouricuri. As informações aqui apresentadas são resultado de muitos anos de trabalho de nós Kariri-Xocó para revitalizar nossa língua. Também saem de discussões entre os autores e outros membros da comunidade durante uma visita de Thea Pitman e Diane Nelson em novembro de 2019. O artigo se constrói de forma multivocal: Thea Pitman e Diane Nelson coordenaram algumas das informações e conduziram uma breve análise sociolinguística, mas Idiane e Nhenety são as vozes principais. 


\section{A HISTÓRIA DA LÍNGUA}

A língua Kariri-Xocó (também conhecida como Dzubukuá Kipeá) pertence à família Kariri do tronco Macro-Jê. A comunidade Kariri-Xocó está localizada em Porto Real do Colégio, estado de Alagoas, a 150 km de Aracaju (SE) e 200 km de Maceió (AL). A área ao redor do baixo Rio Opara (São Francisco) tem uma longa história de atividade missionária portuguesa, incluindo catecismo, assentamento forçado e silenciamento de línguas indígenas. Em 17 de julho de 1873, o Ministério da Agricultura, Empresas e Obras Públicas do Brasil emitiu um decreto formal declarando que os povos indígenas do Nordeste do Brasil estavam "extintos." Isso incluiu grupos conhecidos como os Cropotó, Cariri, Aconan, Ciocó (Xokó) e Prakió, que viviam em torno do assentamento colonial do Colégio na beira do rio Opara (São Francisco) e que falavam suas línguas indígenas (DALLARI, 1978; OLIVEIRA, 1998; MATA, 2018). Durante os cem anos seguintes, os diferentes grupos se uniram uns com os outros, e também com outros membros da comunidade local, tanto pretos como brancos, encontrando maneiras de resistir à total assimilação. Finalmente, os Kariri-Xocó empreenderam um processo de retomada e recuperaram sua aldeia em 1978. ${ }^{1}$ Atualmente, existem cerca de 3.300 membros da comunidade.

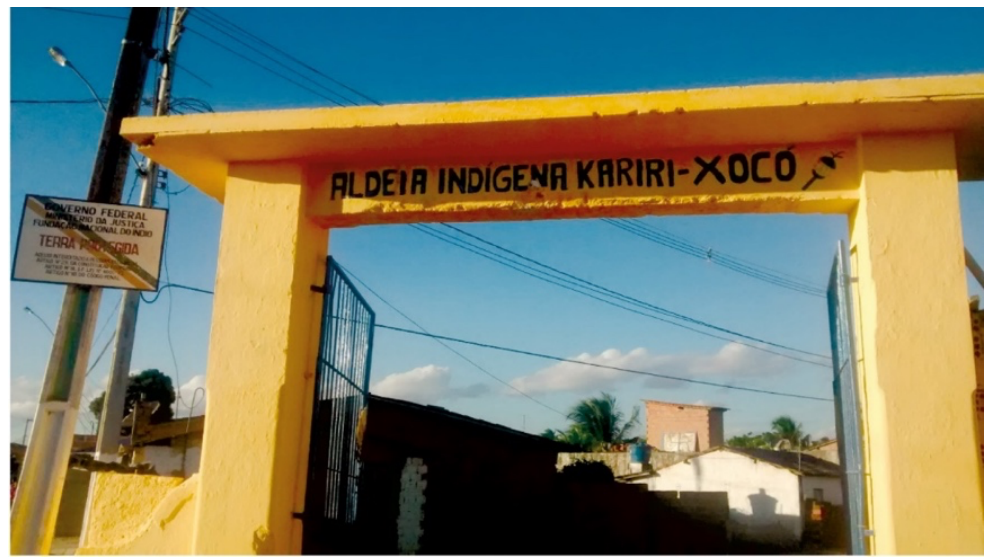

Figura 1. A entrada da aldeia, Porto Real do Colégio, Alagoas. Foto: Thydêwá. 


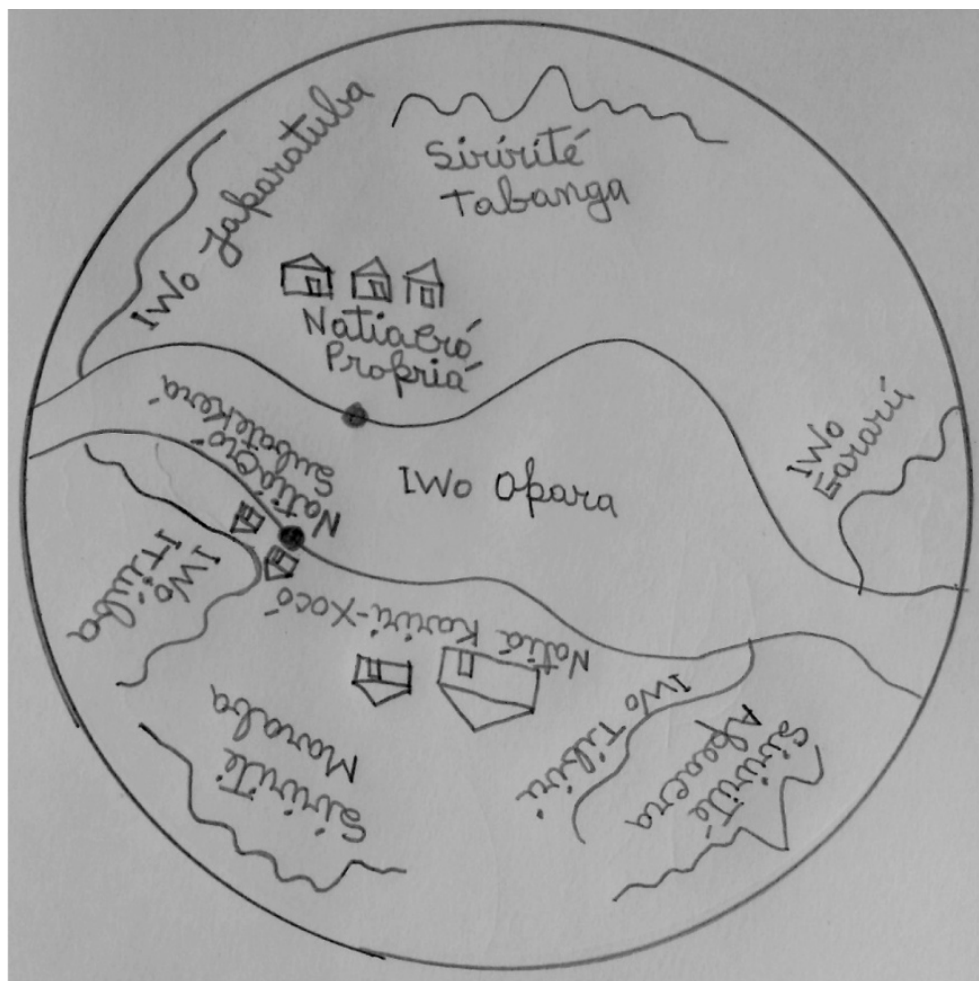

Figura 2. Mapa Kariri-Xocó, desenhado por Nhenety Kariri-Xocó.

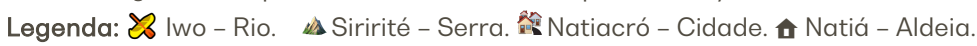

秵 Natiacró Subatekerá - Cidade de Porto Real do Colégio. 且 ơ I wo Opara - Rio São Francisco.

Nhenety: Eu fui treinado pelos Anciões da minha aldeia desde 1963 até 1992, quando aos 29 anos me revelaram alguns segredos e me falaram que já poderia atuar pública e "oficialmente" como "Guardião da Tradição" dos Povos Indígenas do submédio do Opara (São Francisco). Nossa língua indígena estava sendo definida pelos conservadores da academia como "morta," como extinta. Nessa época nenhum Kariri-Xocó poderia enfrentar os "pesquisadores" sem provas e nossas provas estavam, por um lado, no nosso ritual sagrado, no Ouricuri. Ali usávamos palavras e frases, mas estávamos proibidos de revelá-las. Por outro lado a fauna, a flora, os nomes das serras, muito do que estava em volta de nós tinha nomes indígenas mas que já tinham sido antropofagicamente fagocitados pelo Português: capivara, surubim, curimatá, juá, Imburana, Opará, Ipanema. ${ }^{2}$ Nessa época (1984) eu me dediquei a juntar todas as palavras de nosso povo Kariri-Xocó e a estudar nossa língua em campos secretos como dentro de nosso ritual e espiritualidade. Depois (a partir de 1989) me dediquei a estudar todos os "documentos" que existem sobre nossa língua: consultei o

2 Recomendo a leitura do meu escrito, "Toponímia," dentro do livro Somos patrimônio. Mata (2018) também observa que alguns nomes indígenas para plantas medicinais ainda continuavam sendo usados. 
Sr. Manuel Iraminõn, um ancião Xocó que ainda falava a sua língua, ${ }^{3}$ e depois acessei material de arquivo, incluindo uma lista de palavras Kariri (Cariri) de Baptista Siqueira na coleção da FUNAI no Museu do Índio. ${ }^{4}$ Sempre fui muito atento em usar pedagogias indígenas para minha missão de fortalecer a cultura e a língua. Assim que, a partir de 1995, comecei a criar um método próprio para a reaprendizagem do nosso idioma, para empreender a "retomada da nossa língua."

Nhenety tem criado listas de palavras para o idioma Kariri-Xocó e usa palavras e morfemas existentes nas línguas Kariri, Dzubukuá, Natú, Tupi e outras para criar novos termos para inovações tecnológicas e preencher lacunas no léxico. Seguem alguns exemplos:

(1)

$\begin{array}{lll}\text { a. } & \text { wyra-cro-tã } & \text { "drone" } \\ \text { bássaro-pedra-duro } & \\ \text { b. } & \text { "óculos" } \\ & \text { olhos-pedra } & \\ \text { c. } & \text { dzu-tsá-ko } & \text { "café" } \\ \text { d. } & \begin{array}{l}\text { aerã-kuara } \\ \text { folhas-listrado }\end{array} & \end{array}$

Publica estas listas de palavras no seu blog e as distribui para a comunidade via WhatsApp.

\section{O OURICURI E O TORÉ}

Os rituais sagrados do Ouricuri são o fundamento da cultura e espiritualidade Kariri-Xocó. Algumas palavras originais da língua continuam a ser usadas no Ouricuri e novas palavras são recebidas dos ancestrais durante os rituais. Os jovens também formaram vários grupos de Toré que dançam e cantam usando palavras na língua Kariri-Xocó e são incentivados a escrever novas músicas.

Nhenety: eu sou "consultor/tradutor/agitador" do grupo "Soyré" que é composto por uns quinze jovens que cantam e dançam Toré. A cada dia cantam mais na nossa própria língua: com mais frequência e com um repertório maior, e com mais vontade, sentimento, compromisso e orgulho. Com eles faço traduções, explicações do sentido das letras do Toré,

3 O Sr. Manuel Iraminõn morreu em 1994 aos 82 anos de idade.

4 Esta lista de palavras Kariri foi produzida no final da década de 1970 (uma parte dela se encontra no livro de Siqueira, Os Cariris do Nordeste [1978]), mais se baseava em registros mais completos encontrados em textos do início do século XVIII de Martinho de Nantes e de Bernardo de Nantes. 
explicações de nossa cultura e espiritualidade. Apoio outros grupos de Toré e de Rojão ${ }^{5}$ que existem na minha comunidade.

\section{O USO DA TECNOLOGIA}

A tecnologia tem desempenhado um papel fundamental na revitalização da língua KaririXocó. Em 2008, Nhenety iniciou um blog (http://kxnhenety.blogspot.com/), que continua usando como um espaço para fazer upload de listas de palavras e letras de Toré, além de ensaios sobre a história e cultura dos Kariri-Xocó e outros tópicos. A partir de 2017, Nhenety tem "cuidado/administrado/articulado" mais de cem indígenas do povo Kariri-Xocó que aceitaram o convite para participar de um grupo de WhatsApp chamado OKAX. Nesse grupo focamos a cultura e a língua de nosso povo, o vocabulário que vem das tradições e as atualizações linguísticas que precisamos introduzir para falar de coisas do mundo contemporâneo. Também usamos grupos de WhatsApp para compartilhar letras e listas de palavras do Toré, incluindo emojis descritivos junto com as palavras em Kariri-Xocó, com o objetivo de reduzir a dependência da tradução para o Português. Membros da comunidade de várias idades usam os grupos de WhatsApp para trocar mensagens usando a língua Kariri-Xocó.

Em 2019, um novo site foi produzido com a ONG Thydêwá e financiamento da Universidade de Leeds (http://thydewa.org/okax/). O site hospeda informações sobre a língua e cultura Kariri-Xocó, assim como vídeos e um dicionário Português-Kariri-Xocó-Emoji. Esperamos expandir o site OKAX no futuro, à medida que seguimos nossa colaboração. Outros membros da nossa comunidade são ativos nas mídias sociais, incluindo o Facebook, e Nhenety também criou um canal no YouTube (NHENETY/Soyré).

5 Tradicionalmente, o Rojão é uma música cantada em grupos enquanto se faz mutirão. Para um exemplo, ver o 'Rojão do Rio Opara Kariri-Xocó', https://www.youtube.com/watch?v=ulb2h89Euf0. 


\begin{tabular}{|c|c|}
\hline $\begin{array}{l}\text { PURÚ CHII JUREMA } \\
\text { ( Toré Fulor da Jurema ) }\end{array}$ & \\
\hline 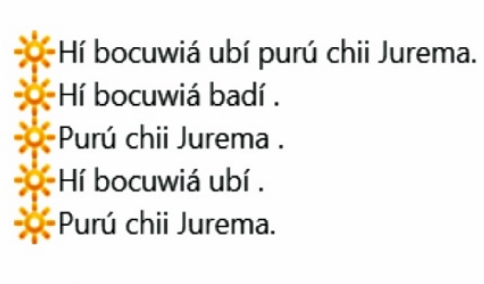 & 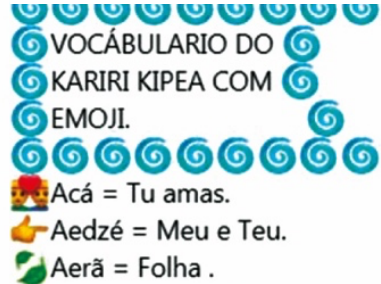 \\
\hline TORÉ FULOR DA JUREMA & $\begin{array}{l}\text { Aindí = Lançar cheiro. } \\
\text { (s) Ambé = Paga. }\end{array}$ \\
\hline Tradução & $\triangle \triangle \Delta$ Amepré = Por culpa. \\
\hline $\begin{array}{l}\text { Eu vou ver fulor da Jurema. } \\
\text { : } \\
\text { Eu vou buscar } \\
\text { Fulor da Jurema. } \\
\text { Fulor da Jurema. }\end{array}$ & $\begin{array}{l}\text { Ane = Sonhos } \\
\text { Andzé = Panos velho. } \\
\text { Anhí = Alma, espírito. } \\
\text { Anhíwonhé = Anjo. } \\
\text { Arancré = Vergonha. } \\
\text { Arankié = Céu. }\end{array}$ \\
\hline
\end{tabular}

Figuras 3 e 4. A letra de um Toré em Kariri-Xocó e Português, e uma das listas de palavras com emojis, ambas mensagens distribuídas por Nhenety no grupo de WhatsApp OKAX.

\section{A ESCOLA DE LÍNGUA KARIRI-XOCÓ E A ALFABETIZAÇÃO}

Em 2018, Idiane Cruz da Silva e seu marido Kawrã Florêncio criaram o "Subatekié Nhunú Kariri-Xocó" (Escola da Língua Kariri-Xocó). Nhenety atua como coordenador pedagógico. Juntos ensinamos principalmente crianças para fortalecê-las cultural e linguisticamente, no sentido de reconhecer, valorizar e afirmar nossa cultura e identidade, e no sentido de reapropriarmos de nossa língua indígena Kariri-Xocó que ficou bastante adormecida e restrita durante quase duzentos anos. A escola começou com um pequeno grupo de crianças e agora tem cerca de 45 alunos, com idades entre quatro e dezesseis anos e habilidades variadas. Às vezes, os adultos também assistem às aulas e às vezes a escola organiza um grupo noturno especificamente para os adultos. Existem dois grupos, um para alunos mais novos/iniciantes, ensinado através do Português, e outro para alunos mais velhos/avançados, ensinado principalmente por imersão no Kariri-Xocó. Idiane baseia-se no vocabulário compartilhado pelo OKAX para ensinar lições temáticas (por exemplo, partes do corpo ou pássaros diferentes) usando um quadro verde tradicional. Os alunos aprendem a ler e escrever na língua Kariri-Xocó. Outros métodos de ensino são interativos e inovadores, incluindo passeios pela natureza e rodas de conversa sobre língua e cultura com Nhenety. Alunos de todas as idades também aprendem a língua através dos Torés. Membros da comunidade, incluindo um dos filhos de ldiane e Kawrã, já produziram vários vídeos pedagógicos feitos com o software VivaVideo ou VideoShow e distribuídos nas contas de Facebook de 
membros da comunidade e nos grupos de WhatsApp de OKAX e dos grupos de Toré. Esses vídeos incluem termos básicos de vocabulário para objetos do cotidiano e Torés legendadas em Português.

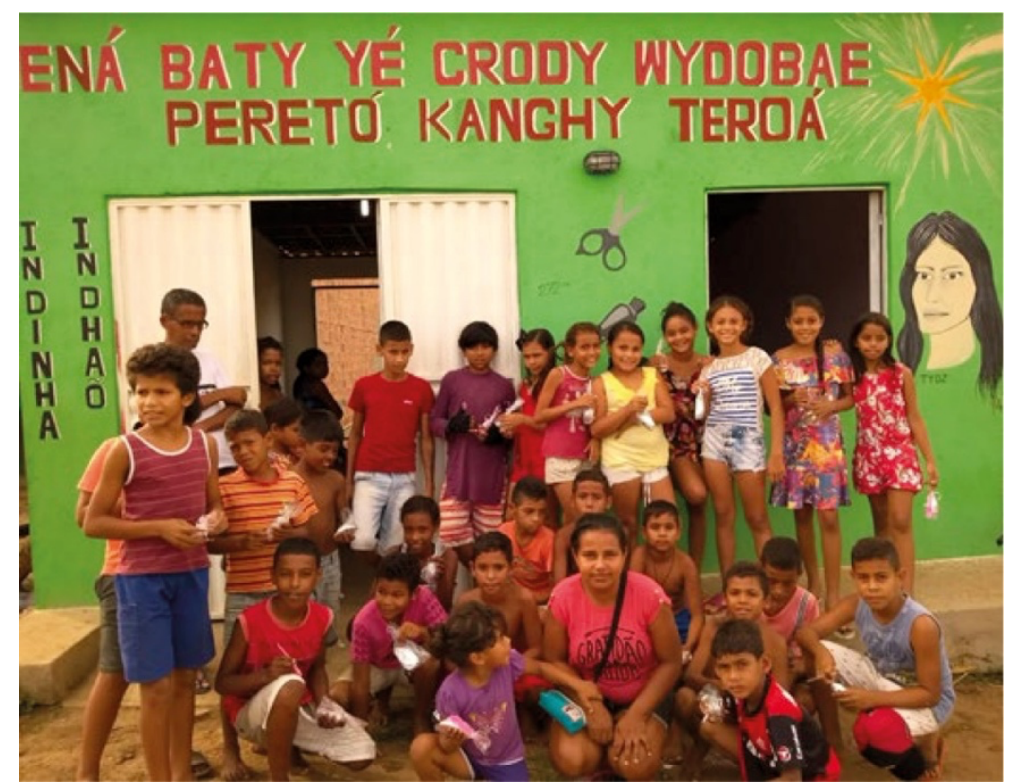

Figura 5. Idiane, Nhenety e os alunos da Subatekié Nhunú Kariri-Xocó. Foto: Elizabete Costa Suzart.

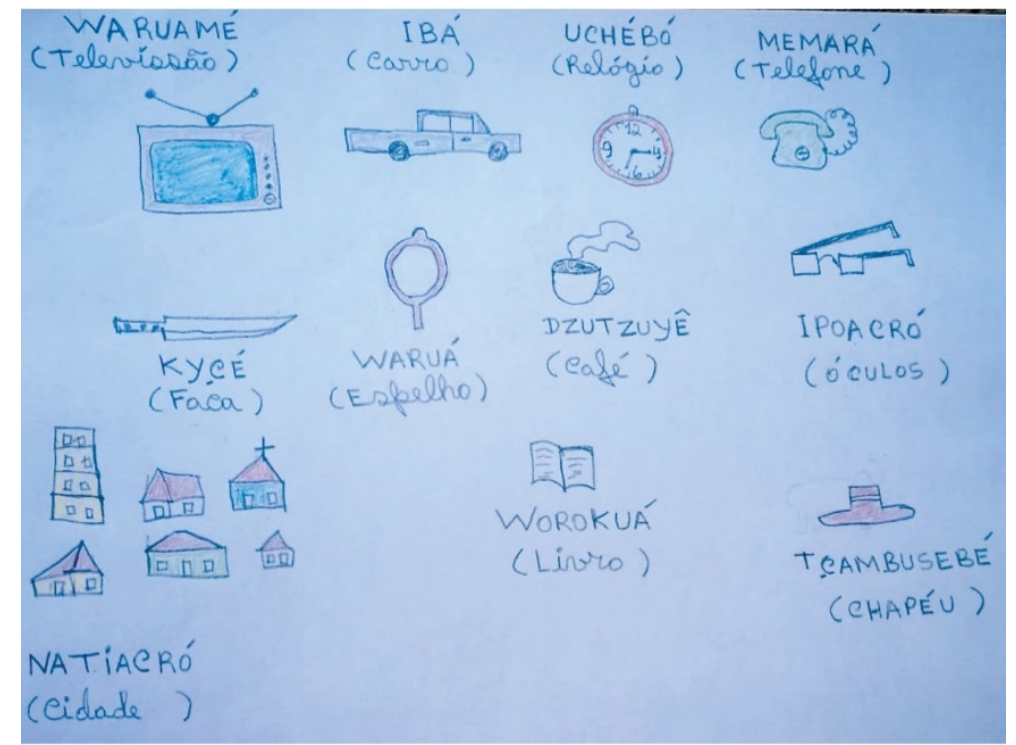

Figura 6. Vocabulário na língua Kariri-Xocó, praticada na escola Subatekié Nhunú Kariri-Xocó.

Desenho: Nhenety Kariri-Xocó. 


\section{O STATUS ATUAL DA LÍNGUA KARIRI-XOCÓ}

Do ponto de vista sociolinguístico, é claro que a língua Kariri-Xocó agora está se expandindo para um número crescente de domínios de uso, nas modalidades escrita e oral. As palavras e frases Kariri-Xocó são usadas por crianças, jovens e adultos em vários contextos, incluindo nos rituais do Ouricuri, na escola, nos grupos de Toré, e nas mensagens em WhatsApp e Facebook. Idiane e seu marido Kawrã falam a língua Kariri-Xocó com seus filhos em casa. Alguns membros da comunidade recebem novas palavras na língua em seus sonhos. O número crescente de domínios de uso, combinado com o fato de crianças e jovens usarem voluntariamente a língua, mostra que os esforços de revitalização foram bem-sucedidos e a língua está aumentando em vitalidade.

O léxico Kariri-Xocó agora inclui cerca de 2300 palavras em listas de palavras publicadas, além de 500 palavras conhecidas apenas por membros da comunidade e que são usadas no Ouricuri. A estrutura sintática da língua Kariri-Xocó tem uma ordem de palavras semelhante à do Português, com uma ordem básica de palavras SujeitoVerbo-Objeto (SVO). Os substantivos precedem ou seguem os adjetivos (o que coincide com as regras do Português), e os possuidores precedem os substantivos como nos exemplos a seguir:

(2) a. dzudé nunú nossa língua

b. bihé tsohó buyõ crody um povo muito forte

c. yee teudiokié grande luta

O sistema ortográfico da língua Kariri-Xocó reflete algumas características sonoras distintas do Português, incluindo os africados /dz/e /ts/, que podem ocorrer na posição inicial da palavra como em "Dzubukuá" e "tsesítea" [mulheres] e ortográficas como w para /u/, como no nome do filho de Idiane e Kawrã, Wmanamy, e y por /i/, como em "ynatekié" [obrigado]. ${ }^{6}$

Os verbos, substantivos e outras classes de palavras no Kariri-Xocó geralmente não são flexionados. No entanto, um marcador plural "-á" aparece em algumas palavras. "Dé"

6 A língua Kariri foi muito documentada por missionários nos séculos XVII e XVIII e por estudiosos a partir do século XIX. Estas pessoas deram forma ao nosso sistema ortográfico. Para um estudo mais novo sobre a língua Kariri/Dzubukuá, ver QUEIROZ (2012). 
significa "mãe" em Kariri-Xocó e, às vezes, "-dé" é usado como um afixo para marcar que um substantivo se refere a uma mulher. Esta estrutura pode ser vista abaixo com palavras formadas a partir da raiz "nhinhó":

(3) a. Nhinhó

b. Nhinho-á

Índio, e também Deus, ser espiritual

c. Nhinho-dé

Índios

d. Nhinho-de-á

Índia mãe

Índias ${ }^{7}$

Idiane e Kawrã também conseguiram que o Kariri-Xocó chegasse a usar-se em um contexto literário. Publicaram uma tradução de um "microconto" da autora Renata Sieiro Fernandes, intitulado “Múrowoy 11” no Kariri-Xocó (CRUZ; FLORÊNCIO, 2019).
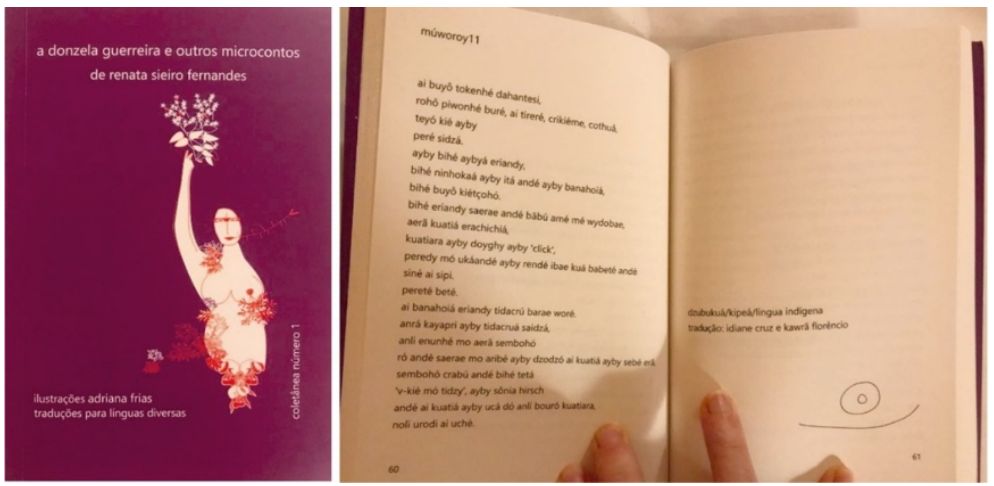

Figuras 7 e 8 . A língua Kariri-Xocó em forma escrita literária. Fotos: Thea Pitman.

\section{A RETOMADA LINGUÍSTICA KARIRI-XOCÓ}

Nhenety: Nosso objetivo é fortalecer nossa cultura. Quando trabalhamos o fortalecimento da língua trabalhamos junto o fortalecimento de nossa cultura. As palavras e frases que escolhemos para o ensino da língua têm a ver com nossa visão do mundo, com nossos valores. A nossa metodologia de ensino/aprendizagem tem a ver com nossa história e com nossa identidade. Fazemos nossos trabalhos em coletivos, através da fraternidade e da solidariedade, fazemos nossas atividades respeitando os ciclos da Natureza, seguindo um calendário cultural que está sintonizado com o ambiental. Para nós tudo é cultura; e não ensinamos e nem aprendemos o Inglês como ensinamos e aprendemos nossa própria língua. Aprendemos o Inglês por uma questão

7 Para mais informações, ver o blog de Nhenety. 
de sobrevivência global, aprendemos tecnicamente a usar este instrumento; a diferença de que quando ensinamos e aprendemos nossa língua o fazemos de forma integral, profunda, completa. Mexer com nossa língua é afirmar nossa identidade, e colocar em perspectiva nossa história, e reapropriar-se de nosso jeito de ser. Nossa língua nos traz autonomia, liberdade, potência, orgulho, pertinência, identificação, nos ancora em nosso povo, nos reafirma com nossa cultura.

Ensinamos nossa língua cantando e dançando, ensinamos com muito respaldo no tradicional ao mesmo tempo em que ensinamos com vídeo, com Whatsapp, valendo-nos das novas tecnologias de comunicação. Ao mesmo tempo em que fortalecemos nossa tradição nos atualizamos no presente. Em nossa prática fazemos com que o "tradicional" e o "moderno" somem, se potenciem em favor do que nós queremos como indígenas.

\section{O SONHO DE IDIANE}

Eridzá anderí erí ané yetçã ubí erí tsohó Kariri Xocó mé dzudé nunú ayby nhenety.

Esse é o meu sonho. Eu vejo o meu povo Kariri-Xocó falando a nossa língua de tradição.

\section{AGRADECIMENTOS}

Os autores gostariam de agradecer a Sebastián Gerlic e a ONG Thydêwá; Wmanamy Kariri-Xocó, Tawaná Kariri-Xocó e os demais membros da comunidade Kariri-Xocó; e Bruna Franchetto e os organizadores do congresso/encontro Viva Língua Viva. A contribuição das pesquisadoras Diane Nelson e Thea Pitman foi financiada pela Universidade de Leeds e pelo projeto de pesquisa Language Acts and Worldmaking (LAWN), financiado pelo ConseIho de Pesquisa sobre Artes e Humanidades do Reino Unido (AHRC).

\section{REFERÊNCIAS}

CRUZ, Idiane; FLORÊNCIO, Kawrã. "Múworoy 11," tradução de "Microconto 11." Em: A donzela guerreira e outros microcontos. FERNANDES, Renata Sieiro. São Paulo: Programa de Ação Cultural, Governo do Estado de São Paulo, 2019, p. 60-61.

DALLARI, Dalmo de Abreu. "O índio, sua capacidade jurídica e suas terras." Em: A questão da emancipação, Cadernos da Comissão Pró-Índio, n. 1, São Paulo: Global Editora, 1978. p. 77-82.

KARIRI-XOCÓ, Nhenety. Blog. 2008-presente. Disponível em: http://kxnhenety.blogspot.com/.

KARIRI-XOCÓ, Nhenety. Canal de YouTube. 2009-presente. Disponível em:

https://www.youtube.com/user/Nhenety/. 
KARIRI-XOCÓ, Nhenety. "Toponimia.” Em: Índios na visão dos índios: Somos patrimônio, editado por GERLIC, Sebastián (org). Salvador: Thydêwá, 2011, p. 30-32. Disponível em:

http://www.thydewa.org/downloads/somos_patrimonio.pdf.

MATA, Vera Lúcia Calheiros. "Kariri-Xocó”. 2018. Disponível em: https://pib.socioambiental.org/pt/Povo:KaririXokó.

OKAX. Site da internet. 2019-presente. Disponível em: http://thydewa.org/okax/.

OLIVEIRA, João Pacheco de. "Uma etnologia dos 'índios misturados'? Situação colonial, territorialização e fluxos culturais.” Mana, 1998. v. 4, n. 1. Disponível em:

https://www.scielo.br/scielo.php?script=sci_arttext\&pid=\$0104-93131998000100003.

QUEIROZ, José Márcio Correia de. Um estudo gramatical da língua Dzubukuá, família Karirí. 2012.Tese de doutorado. Universidade Federal da Paraíba, João Pessoa. Disponível em:

https://repositorio.ufpb.br/ispui/handle/tede/6358/.

SIQUEIRA, Baptista. Os Cariris do Nordeste. Rio de Janeiro: Cátedra, 1978. 